\title{
La iglesia de Incahuasi. Notas sobre antropología simétrica, arquitectura e historia en los Andes peruanos septentrionales (Ferreñafe, Lambayeque)
}

\author{
Juan Javier RIVERA ANDÍA \\ Universidad Autónoma de Barcelona \\ jjriveraandia@gmail.com
}

Recibido: 31 de julio de 2015

Aceptado: 27 de noviembre de 2015

\begin{abstract}
RESUMEN
La sierra de Lambayeque conserva un templo virreinal con una arquitectura y una historia singulares en los Andes peruanos: la iglesia de Incahuasi. Este trabajo inicia su descripción detallada en diálogo con la etnografía andina y con la historiografía de esta región tan poco estudiada de los Andes y examina las posibilidades de considerar dos cuestiones principales: el contexto de aparición, edificación y papel histórico del templo como dispositivo particular en la lucha por el control sobre la tierra, y su carácter -tal cual lo expresan las gentes de Incahuasi- en tanto que sujeto ontológico integrante del mundo. Con tal fin, nos apoyamos en aquellos elementos que sugieren su carácter antropomorfo y su papel «amansador» de las desventuras del medioambiente. A modo de propuesta preliminar se presentan los esquemas sincrónicos y los procesos diacrónicos por medio de los cuales el templo y los hombres se constituyen mutuamente.
\end{abstract}

Palabras clave: Quechua Cañaris, Andes, ritual, arquitectura.

\section{The Church of Incahuasi. Notes on Symmetrical Anthropology, Architecture, and History in Northern Peruvian Andes (Ferreñafe, Lambayeque)}

\begin{abstract}
Lambayeque saw retains a colonial temple with a unique architecture and history in the Peruvian Andes: the church of Incahuasi. This paper begins its detailed description in dialogue with ethnography and historiography of this region so little studied in the Andes, and examines the possibilities to consider two main issues: the context of developing, building and historical role of the temple as device particularly in the struggle for control over land, and its character -as the people of Incahuasi express- as ontological subject into the world. So, we rely on those elements that suggest their anthropomorphic character and its role «tamer» of the misadventures of the environment. Thus, as a preliminary proposal, we present the schemes of synchronic and diachronic processes through both temple and men are mutually.
\end{abstract}

Key words: Cañaris Quechua, Andes, ritual, architecture.

Sumario: 1. Introducción. 2. Apuntes sobre un cierto diálogo entre la antropología y la arquitectura. 3. ¿Qué construyeron los incahuasinos cuando fundaron un templo clandestino? Notas sobre un sujeto antropomorfo y amansador. 4. Una mutua constitución entre los hombres y el templo: cartografías y calendarios derivados de la apropiación de la tierra. 5. Referencias bibliográficas.

Architecture as a discipline that shares with art and anthropology a concern to explore the creative process that give rise to the environments we inhabit, and the ways we perceive them (Ingold 2013: 10). 


\section{Introducción}

En la sierra de Lambayeque, a más de 3.000 metros de altura, se yergue un templo virreinal ${ }^{1}$ construido por los indios del área Cañaris ${ }^{2}$ con el propósito de fundar un nuevo pueblo, un pueblo hecho por y para ellos (Figura 1). Dicho pueblo está habitado hoy por los miembros de la comunidad campesina San Pablo de Incahuasi y es también la capital del distrito del mismo nombre adscrito a la provincia de Ferreñafe, en el departamento peruano de Lambayeque. Desde la plaza al lado de la iglesia puede dominarse un paisaje enorme hacia el occidente.

En los siguientes apartados revisaremos brevemente y a la luz de algunas consideraciones teóricas y etnográficas previas, tomando en cuenta aquellos aspectos de nuestra experiencia de campo iluminados por lecturas posteriores como las de Tim Ingold, las posibilidades de tratar este templo como un sujeto. La hipótesis que proponemos aquí es que el templo de Incahuasi constituye, no solo un sujeto en el mundo actualmente compuesto por los incahuasinos, sino también una suerte de sujeto histórico, que se ha desarrollado en función de cierto contexto regional y que sigue jugando un papel ordenador crucial en la organización y el devenir de este pueblo.

A la luz de esta hipótesis, retomaremos muy brevemente el papel de este templo en la historia de la villa de Incahuasi. Estos datos han sido analizados en un trabajo distinto (Rivera Andía en prensa) donde trazamos una historia que, a pesar de ser bastante parcial, permite vislumbrar cómo esta villa pasó de ser una fundación clandestina en los años finales del virreinato, a consagrarse como una capital de distrito en la república, atravesando por un conjunto de operaciones tanto legales -la compra de tierras a los caciques o los pleitos contra los «vecinos» de regiones adyacentescomo ilegales -haber instalado, en contra de lo dispuesto en su época, una «capilla» con «campana» y «rollo»y, consecuentemente, haber nombrado un «alcalde» y un «alguacil» (Huertas 1996)-.

Además de esbozar el período histórico en el que surge esta contravención de las normas, discutiremos también qué es en efecto lo que surge cuando los indios del área Cañaris construyen su templo y fundan Incahuasi. Nos detendremos, pues, a resaltar aquellos elementos que sugieren una marcada antropomorfización del templo y aquellos otros que muestran su papel «amansador» de los peligros del mundo durante los rituales de esta comarca.

\footnotetext{
1 La descripción cabal de este templo, de su constitución material y de sus usos actuales está aún por hacerse aunque han aparecido noticias recientes (Rivera Andía 2014b). En los últimos dos años ha aparecido un notable estudio sobre los templos virreinales de Lambayeque que dedica un párrafo al templo de Incahuasi (Castañeda et al. 2015: 184). Además, Alfredo Carrasco (2014) ha comenzado a publicar una etnografía de la sierra de Lambayeque sin precedentes en la que incluye nuevas informaciones sobre la iglesia de Incahuasi. También hace poco, un folleto (Martínez 2014) ha recogido algunos datos dispersos en los estudios de Vreeland (1993), Díaz y Guevara (2007), CIDEC (2013), Rivera Andía (2011), Shaver (1989 y 1992) y Groenewald (2011a y 2011b).

2 Valdría la pena aclarar que el área que llamamos Cañaris, tanto para sus habitantes como para los autores de los pocos trabajos realizados hasta hoy, no es uno sino varios lugares cuyos rasgos compartidos los distinguen del mundo que lo rodea (Alva 1989, 1995, 2008, 2009, 2013; Carrasco 2008, 2009 y 2010; Castañeda 1981; Fernández 2009, 2010, 2011 y 2013; Huamán 2008; Rivera Andía 2010a, 2010b, 2011, 2013a y 2013b; Sax 2014).
} 


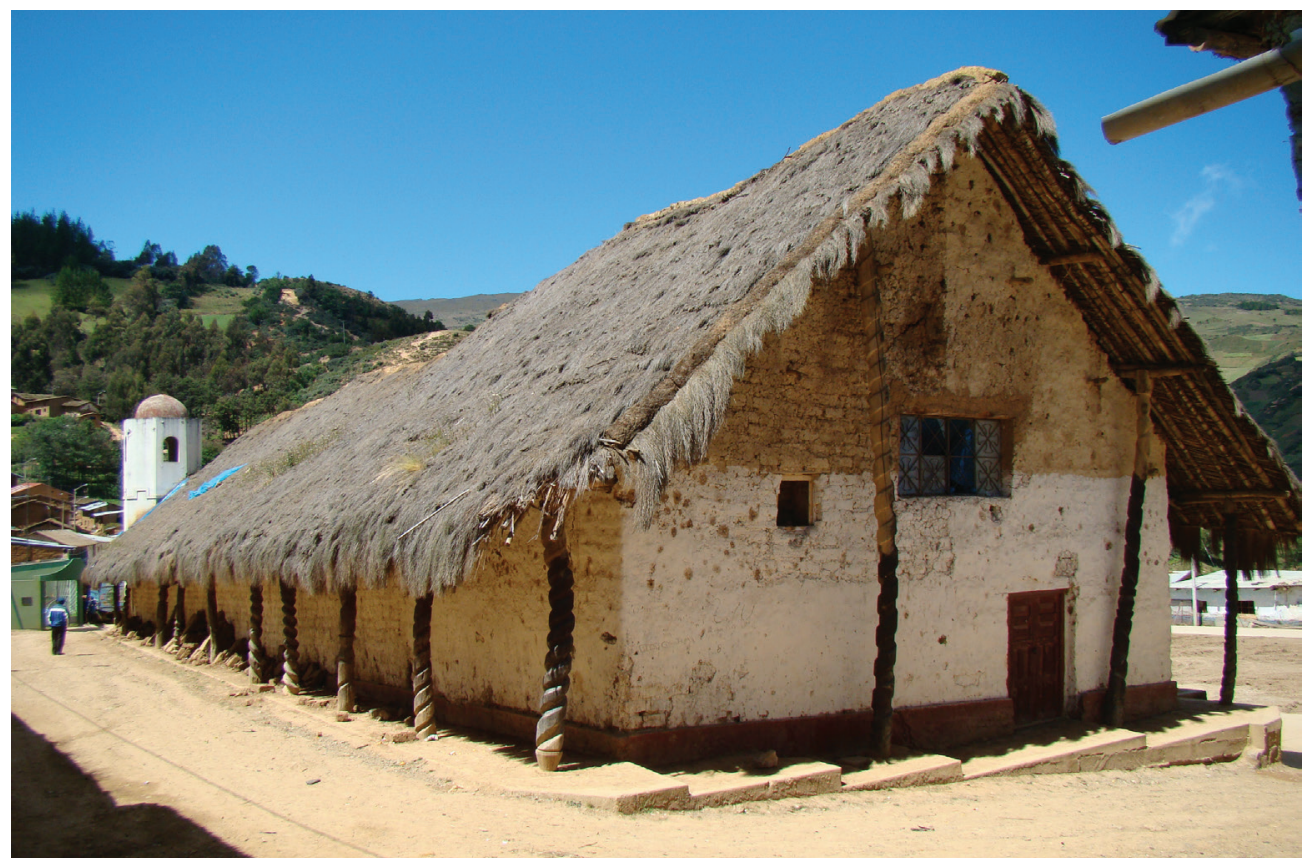

Figura 1: Vista exterior de la iglesia de Incahuasi.

Una vez visto el contexto histórico en el que surge el templo de Incahuasi y las características que éste tiene para los incahuasinos, abordaremos finalmente lo que entendemos, por el momento, como una mutua constitución entre estos y aquel. Por un lado, destacaremos algunos aspectos observados durante nuestro trabajo de campo en Incahuasi que nos parecen justificar el planteamiento de la iglesia como un sujeto que se constituye mutuamente con los incahuasinos que la edificaron hace más de dos siglos y medio y con sus descendientes. Y observaremos que la iglesia de Incahuasi constituye, en el plano sincrónico, una suerte de cartografía no solo de las tierras y los cerros que circundan el pueblo, sino sobre todo de la organización de los miembros de la comunidad. La explicación de este rasgo particular del templo de Incahuasi, como veremos, no parece posible si no nos remitimos, simultáneamente, tanto a patrones estructurales andinos (por ejemplo, el llamado «dualismo») como a la particular historia de la constitución de este pueblo en el área quechuahablante de Cañaris.

Por otro lado, destacaremos los aspectos diacrónicos de esta mutua constitución entre los incahuasinos y esta entidad no-humana específica, abordando las características del templo de Incahuasi que atañen al mundo mitológico y ritual. Así, por ejemplo, encontramos no solo relatos orales sobre la fundación de capillas y templos a partir de hechos extraordinarios que alteran el medioambiente de los hombres (Morote 1988), sino también el ordenamiento temporal sustentado por las celebraciones religiosas vinculadas a las celebraciones religiosas andinas, incluyendo aquellas vinculadas al llamado «dualismo» o «estructuralismo» en esta región (Palomino 1984, Zuidema 1995). 
Lo que proponemos aquí es considerar un templo virreinal indígena, no como un objeto diseñado y construido por los miembros de una sociedad que habrían impreso en ella un conjunto de técnicas manuales y una especie de «cultura viva» y que merecería, por ejemplo, ser víctima de la fiebre «patrimonializante» que aqueja las políticas públicas culturales en el Perú neoliberal de hoy, sino más bien como un sujeto simétrico, es decir, uno con el mismo estatus ontológico que los incahuasinos y que otros elementos fundamentales del mundo que estos componen, como los cerros o las lagunas que afectan su destino. Intentaremos abordar y a modo de tentativa preliminar el proceso histórico por medio del cual ambos, este templo-sujeto y los hombres, se han constituido mutuamente.

\section{Apuntes sobre un cierto diálogo entre la antropología y la arquitectura}

A lo largo de su obra, Tim Ingold (2013) ha venido ampliando sus perspectivas desde la antropología hasta diversas disciplinas como la Arqueología, el Arte y la Arquitectura. Para este autor, todas estas disciplinas serían dominios ideales para lo que él llama pensar por medio de la práctica (making).

Las características que acercan la Antropología al Arte son el carácter especulativo, experimental y abierto de ambos ${ }^{3}$. Esta asociación de la Antropología con procesos creativos y transformadores puede ilustrarse por medio de aquellos estudios de cultura material en los que persistentemente se omite el proceso de producción en beneficio del objeto ya terminado. Para Ingold (2013: 7) esto muestra el constante desdén, tanto de la creatividad del proceso productivo, como de las corrientes generativas de los materiales y la consciencia sensorial de los fabricantes: «Making... is a process of correspondence... the drawing out... of potentials immanent in a world of becoming» (Ingold 2013: 31).

Organismo y artefacto sólo se diferenciarían, para Ingold, por la extensión del involucramiento humano en la generación de la forma: ambos se desarrollan y ambos son hechos. Se trataría, pues, de una diferencia que es sólo de grado, no de tipo (Ingold 2013: 22). Por medio de ejemplos como la construcción de montículos, el tejido de canastas, la fabricación de ladrillos o de hachas de mano, Ingold nos acerca a la perspectiva de unos flujos materiales y unas corrientes de consciencia sensorial, donde imágenes y objetos se dan forma recíprocamente: «the essential relation in a world in formation... is not between form and matter but between forces and materials» (Ingold 2013: 45).

Ingold pone en cuestión el hilemorfismo, el axioma que sustenta la distinción entre lo natural y lo artificial, donde la imposición de la forma pura elevaría una materia cruda, naturalmente dada, a un estado artificial. Reitera su desacuerdo con la aparente necesidad de un diseño y la prioridad de la imposición de la forma sobre el mundo:

«...the creativity of the «messy practices» that give rise to real buildings... all involve care, judgement and aforethought, and are carried on within worldly fields of forces

\footnotetext{
3 Si la Antropología se lleva a cabo en un proceso vital que ejerce transformaciones en ese mismo proceso, los productos de la Etnografía serían solo unas descripciones realizadas con un propósito documental.
} 
and relations. None can be placed unequivocally on one side or the other of any distinction of fundamental ontological import, such us between intellectual conception and mechanical execution. On what grounds then, if at all, can architecture be distinguished from building...?» (Ingold 2013: 59).

Insistiendo en que ningún diseño debería separarse de la hechura de un objeto, Ingold también cuestiona la distinción entre arquitectura y construcción:

«Do we not rather have to conclude of things made or built, as much as of things grown, that they are originating all the time?» (Ingold 2013: 81) ${ }^{4}$. Aduce que las actividades relacionadas con el uso de un edificio no son realmente distintas de aquellas ligadas a su construcción: «the intentionality of skilled practice inheres in the action itself, in its qualities of attentiveness and response, whether or not any prior intentions are affixed to it» (Ingold 2013: 43).

Quizá sea útil recordar también una de las consideraciones que Tim Ingold hace en una reciente conversación con Philippe Descola, en la que sugiere el carácter intrínsecamente diacrónico de sus propuestas:

«C'est à la édification de ce pont [entre la anthropologie social et la biologie du développement] que je me consacre... ainsi que a la mise en évidence de la nécessité d'étudier les êtres humains... au sein d'un environnement. Il s'agit d'un processus historique. En me concentrant sur l'étude de ce processus, je me suis davantage intéressé à distinguer les ontogénies (c'est-à-dire les différents chemins de développement) que les ontologies... J' essaie de ne plus penser en termes d'animisme... mais plutôt en termes de processus animiques (ou non-animiques) en développment» (Ingold y Descola 2014: 37 ; el énfasis es nuestro).

Esta sugerencia de Ingold atañe a la «biología del desarrollo», en concordancia con su interés recurrente en las relaciones entre los seres humanos y otros organismos de su medioambiente. Además, en otros trabajos del mismo autor, encontramos incluso un énfasis en la continuidad entre lo que por un lado consideramos como «artificial» -un templo- y, por el otro, como «natural» - un cerro-. Ingold ilustra su propuesta por medio del caso del montículo: producto acumulativo de todo tipo de actividades humanas y no-humanas realizadas a largo plazo, un montículo es, al mismo tiempo, más artificial que una montaña, pero más natural que un monumento. ¿Qué presunciones tácitas hacemos, entonces, cuando distinguimos un cerro de una iglesia y en qué dirección nos llevan? Evidentemente, lo que haremos ahora es solamente retomar este cuestionamiento y ocuparnos del templo de Incahuasi como de un elemento del medioambiente de los incahuasinos que, como ellos y otros seres biológicos, ha pasado por un proceso de desarrollo. A continuación nos limitaremos a detallar algunos de los escasos datos disponibles sobre este proceso histórico, que hemos resumido en otra parte (Rivera Andía en prensa).

\footnotetext{
4 Así, por ejemplo, una ideología como la que sustenta la «salvaguardia del patrimonio» podría considerarse en términos de un «characteristically modernist desire to preserve in perpetuity what is imagined to have been a historically completed form, the perfect realization of an original design» (Ingold 2013: 57).
} 


\section{3. ¿Qué construyeron los incahuasinos cuando fundaron un templo clandestino? Notas sobre un sujeto antropomorfo y amansador}

En otra publicación (Rivera Andía en prensa), hemos descrito, con cierto detalle, el papel fundamental del templo de Incahuasi en la apropiación o recuperación de tierras por parte de los indígenas del área Cañaris. Estas reapropiaciones y conflictos sucedidos, en su mayoría, entre los siglos XVII y XVIII en el contexto de un enfrentamiento con las haciendas vecinas, incluyen desde transacciones legítimas, como la compra de tierras a la «cacica» de Cañaris, y reclamaciones por vías institucionales, como aquel ante el virrey sobre el diezmo a la iglesia, hasta rebeliones violentas como las de los indios de Incahuasi, y fundaciones clandestinas, como la de su templo.

Aquí, en este apartado, queremos considerar la posibilidad de que el «medio natural» de Incahuasi, como lo llamara el eminente estudioso italiano Antonio Raimondi (1965) a su paso por esta comarca, esté no solo representado, sino también constituido por su templo. Es decir, vamos a considerar este templo como un sujeto con un papel tan constitutivo como el de los mismos incahuasinos o el de otras entidades de su entorno. Así, nos acercaremos al carácter antropomorfo del templo y a su papel de «amansador» de las entidades no-humanas que circundan Incahuasi y pueblan los llamados «encantos» de los cerros y lagunas.

Comenzaremos, pues, con una característica crucial del templo: su carácter antropomorfo, que tiene, al menos, dos expresiones. Una es el tallado de rostros humanos en las columnas salomónicas exteriores que rodean el templo y sostienen su techo . Este tallado de rostros humanos en las columnas de madera se realiza, aproximadamente, cada vez que debe reemplazarse el techo de la iglesia, como una forma de prevenir daños en los muros debido a filtraciones durante las lluvias.

Para comprender mejor el contexto en el que se realiza esta operación, necesitamos, pues, acercarnos a los rituales andinos en torno al retechado de viviendas.

\footnotetext{
5 No solo este tallado sino la existencia misma de estas columnas exteriores parece constituir una de las características más peculiares de la arquitectura de esta iglesia. El templo está rodeado por veintisiete columnas torsas que tienen la siguiente distribución (siempre desde el punto de vista de quien mira la entrada principal del templo): trece en el lado izquierdo, doce en el derecho y dos más en la parte posterior (en la parte delantera del templo, no existen columnas). Nótese que aquí también existe una asimetría entre las dos mitades (en la que el lado que aquí llamamos «izquierdo» suele superar a su opuesto). También es digno de mención que casi todas las columnas están adscritas a una imagen religiosa, una cofradía, aquella que la celebra, y un caserío: aquel donde vive la familia que dirige la cofradía, específico. Así, en la mitad izquierda, de adelante hacia atrás, encontramos sólo diez columnas (de un total de trece) adscritas a: la Virgen de los Dolores (y Tungula), Domingo de Pascua (y Tungula), Todos los Santos (y Huar Huar), Santa Rosalía (y Tungula), Niño Dios de Reyes (y Totora), San Juan (y La Tranca), Santa Ana (y Tolojpampa), Santa Rosa de Lima (y Tasajera), Asunción del Señor (y Tasajera), Cruz de Mayo (y Playa). En la mitad derecha y también de adelante hacia atrás, encontramos sólo once columnas (de un total de doce) adscritas a: San Andrés (y Sinchihual), Virgen de la Candelaria (y Huasicaj), Martes de Semana Santa (y Huasicaj), Lunes Santo (y Huasicaj), San Nicolás Tolentino (y Huasicaj), Jueves Santo (y Machaicaj), San Antonio (y Totorita), Corpus Christi (e Incahuasi), San Francisco de Asís (y Totorita), San Miguel (e Incahuasi) y Virgen Purísima (e Incahuasi). Como puede apreciarse, hay una correlación espacial más o menos aproximada: las columnas suelen estar adscritas al mismo caserío al que le corresponde la sección del techo que aquellas sostienen. Hay también, sin embargo, notables vacíos e inversiones.
} 
Aunque los ritos sobre el techado de casas familiares en la sierra del Perú ${ }^{6}$ no parecen haber llamado mucho la atención de la todavía escasa etnografía andina, al menos podemos contar con ciertas noticias que dan una idea de su complejidad. En contraste con las noticias que hemos podido recopilar sobre este rito (Rivera Andía 2014a), casi nada hemos encontrado que pueda ser siquiera similar a lo que se lleva a cabo en la iglesia de Incahuasi.

En el caso del techado de la iglesia de Incahuasi, éste difiere del techado de casas en los Andes, al menos, en dos aspectos. En primer lugar, se trata de un espacio colectivo, no de una familia individual. En esta medida sus labores y rituales no incluyen sólo a una familia y sus aliados, sino al conjunto de miembros de la comunidad. Al mismo tiempo, mientras algunas secuencias rituales en los casos de las viviendas familiares se obvian, otras sólo aparecen en el caso de la iglesia ${ }^{7}$. En segundo lugar, el techado de la iglesia contiene un ritual que, como dijimos, no ha sido descrito en el caso de los techados rituales de casas - estudiados en profundidad por Peter Gose $(1991)^{8}$ - la «landa», que constituye la segunda expresión del proceso de antropomorfización al que aludíamos a propósito de las columnas entorchadas con rostros tallados en su madera. «Landa» es el nombre dado en toda el área Cañaris al ritual de raigambre prehispánica (tal como lo describiera, por ejemplo, el Inca Garcilaso de la Vega) ${ }^{9}$, conocido en otras regiones andinas como «corta-pelo».

El rito consiste, en su estructura general panandina, en una reunión de los parientes y aliados de los padres del niño, quienes, a cambio de cortar un mechón de sus cabellos, ofrecen diversos dones cuidadosamente consignados para el futuro patrimonio del infante ${ }^{10}$. Encontramos aquí, pues, una analogía explícita entre la iglesia y un ser humano, concretamente un niño que está por cumplir uno de los pasos iniciales para su progresiva entrada en la sociedad de los hombres. Esta analogía se vuelve explícita cuando, al final del retechado, la iglesia de Incahuasi es sometida a un «landa», del mismo modo que sucede con los niños que comienzan así a entrar en la vida social del pueblo (Figura 2). Cada lustro o década, cuando se procede a cortar por medio de

6 Llamados «zafa casa», qinchullay (en Junín), wasichakuy (en Ayacucho) o « flechada » (en Jujuy, al noroeste de la Argentina), estos rituales tienen un objetivo práctico fundamental: el techado de una casa recién construida o la renovación de la techumbre de una casa ya terminada.

7 El techado de viviendas familiares con materiales de origen vegetal es cada vez menos frecuente y fácil de observar, pues el uso del techo de zinc ha predominado en toda el área Cañaris, como en el resto de los Andes.

8 Para otras perspectivas, igualmente interesantes y etnográficamente informadas, acerca de la percepción y evolución de las viviendas en el mundo ritual y cotidiano de los Andes, véase Muñoz (2012) y Sax (2014, cap. 5).

9 Garcilaso sitúa este ritual de iniciación como anterior, en imprescindible, al famoso warachikuy, cuyas resonancias en rituales de iniciación y ritos ganaderos contemporáneos, hemos sugerido anteriormente (Rivera Andía 2003).

10 Los donadores más importantes suelen ser los que han sido designados por los padres como los «padrinos». En Incahuasi, y en toda el área Cañaris, se celebra con una música particular tocada con charanga o cañareja y con letras de canciones que se adaptan al sexo del niño (Rivera Andía et al. 2015). El «landa» del área Cañaris contiene además secuencias rituales que no se han registrado, hasta donde sabemos, en otras regiones andinas: el cabello no lo guardan los padres, como lo describe Garcilaso y otras descripciones más contemporáneas, sino que es llevado por una comparsa que baila al son del «landa» tocado por el charanguero hasta el bosque. Allí se busca una bromilácea particularmente grande o un termitero particularmente sólido para ocultar allí los cabellos del niño o niña que ha entrado ya en el mundo de los hombres. 


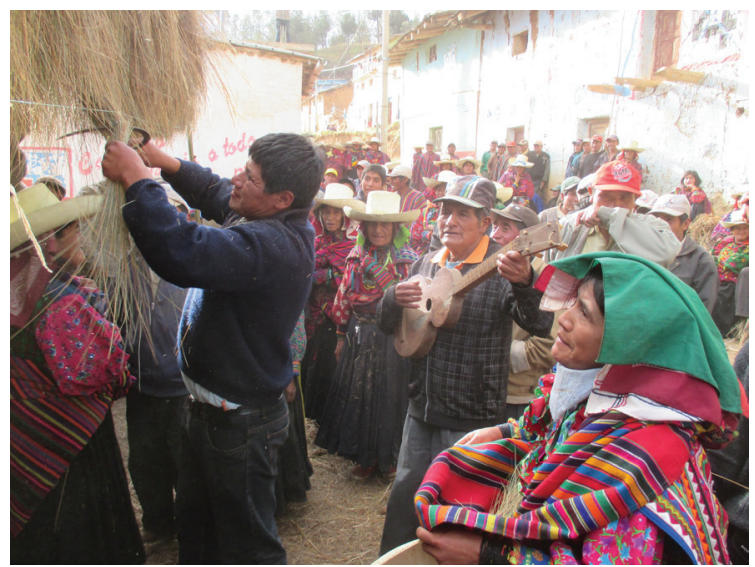

Figura 2: Landa del techo de la iglesia de Incahuasi (fotografía de Alfredo Carrasco).

procedimientos rituales específicos que no podemos detallar aquí los restos de paja que sobresalen en ambos aleros, se equipara, pues, la paja del techo con los cabellos de los pequeños a los que se somete al ritual del primer corte de los cabellos en buena parte de los Andes ${ }^{11}$.

El segundo aspecto característico del templo de Incahuasi es su papel de «amansador» -en un sentido que dialoga con el proceso descrito por Tristan Platt (2001) con respecto a lo que denomina el «feto agresivo» en el sur de los Andes-. En las celebraciones que cobija la iglesia, y de modo análogo a como convierte un pantano en un pueblo, el templo sirve para amansar los poderes del medioambiente que son dañinos. La iglesia puede conjurar, por ejemplo, el exceso de viento, como sucede en Penachí cuando no se coloca la cruz de manera perfectamente perpendicular al suelo. Pero también puede vencer los mismos poderes del demonio, tal como sucede en Cañaris, cuando se cuelga al diablo en persona dentro de la iglesia en Semana Santa. En el caso de Incahuasi, los fieles de la Virgen de las Mercedes, dejan tierra de sus parcelas y vellones de sus animales a los pies de la imagen para así proteger sus cultivos y ganados de las inclemencias del tiempo y promover su fertilidad.

\section{Una mutua constitución entre los hombres y el templo: cartografías y calendarios derivados de la apropiación de la tierra}

En este último apartado, nos proponemos, en primer lugar, reunir las noticias más recientes acerca de los esfuerzos de los campesinos quechua parlantes por acceder a la tierra. En segundo lugar, queremos mostrar cómo esta continuación de sus luchas anteriores no solo ha producido el surgimiento del templo de Incahuasi, sino que, además, ha hecho del mismo un sujeto. Queremos subrayar, así, que este sujeto tiene, además de un desarrollo en el tiempo, también un papel activo en la organización y por tanto el destino de lo incahuasinos.

11 En la vecina provincia cajamarquina de Cutervo encontramos un nombre similar: «landaruto». En regiones tan lejanas como Jujuy (en el norte de Argentina), se le denomina «corte de simbas». 
Esta característica del templo se expresaría, por un lado, en la función «cartográfica» o sincrónica que cumple hoy el templo de Incahuasi. Una función que es visible en la correspondencia entre las familias incahuasinas y varios de sus componentes: las imágenes veneradas de su interior, las secciones en que se divide techo y las columnas entorchadas exteriores. En efecto, cada uno de estos elementos está cuidadosamente adscrito esto es, debe ser construido, mantenido y renovado, a las distintas familias, cofradías y caseríos que componen Incahuasi.

Al mismo tiempo, podemos notar dos aspectos que aluden a la dimensión diacrónica de esta mutua constitución de los incahuasinos y su templo. Uno es de carácter mítico: la dimensión cosmogónica del templo que se expresa en los mitos en torno a su fundación, simultánea con la transformación del medioambiente y con la creación de la villa. El otro aspecto es de carácter ritual. El templo cumple, evidentemente, un papel ordenador del tiempo, por ejemplo, por medio del ciclo ritual en torno a las imágenes que alberga.

A continuación esbozaremos el último siglo de los avatares de la lucha por la tierra en el área Cañaris y las expresiones sincrónicas y diacrónicas del papel que el templo de Incahuasi ha jugado en la misma.

El viaje de Antonio Raimondi, al que aludimos más arriba (Rivera Andía en prensa), coincide no solo con una etapa de crecimiento económico en la costa norte del Perú, sustentada en la expansión de la agroindustria azucarera de exportación, sino también con la creación, en 1872, durante el gobierno de José Balta, del departamento de Lambayeque. Al nuevo departamento quedarían adscritos los pueblos de indios de Penachí, Cañaris e Incahuasi, esto es, la mayor parte del área Cañaris, que dejan así su histórica adscripción a Piura. Sin embargo, las haciendas del área Cañaris (como Janque, Moyán o Canchachalá) no tuvieron la misma suerte que las costeñas, manteniéndose menos dinámicas y menos relacionadas con el exterior (Taylor et al. 2006: 269). Tal era la situación, por ejemplo, e incluso a principios del siglo XX, del más de medio centenar de fundos y de la veintena de haciendas que se encontraban en la jurisdicción del distrito de Salas (Bachmann 1921: 368).

En las puertas del siglo XX, pues, el control de la tierra seguía siendo la historia de una pugna en el área Cañaris. Así, haciendas como las de Moyán y Canchachalá, de propiedad de la familia González, en la actual jurisdicción del distrito de Incahuasi, se disputaban con los indígenas el control sobre la mano de obra, las tierras y -con el apoyo tácito de la Ley Liberal del Agua, vigente desde 1902 hasta 1936,-- el acceso al agua de riego (Taylor et al. 2006: 256). Esta disputa por el acceso al agua y por el control de la tierra podría traducirse, en términos arquitectónicos, como una entre las casas hacienda y los templos de indios, de los que ha sobrevivido hasta hoy, en el área Cañaris, solo el de Incahuasi. Los hacendados y los sacerdotes, al menos en el caso de Incahuasi, parecen de hecho haberse disputado la ascendencia sobre los indios. Así parece sugerirlo un breve y amargo testimonio escrito por José Mercedes Díaz Bernal, sacerdote de Incahuasi, el 22 de agosto de 1895 (Figura 3), advirtiendo a sus sucesores sobre las andanzas de los hacendados González:

«Encargo a mis compañeros que vengan de curas a [este] pueblo que no se lleven de los Señores Gonzales ta[nto] mayores como de los hijos porque son muy [ilegible] la amistad con todos, pero $\mathrm{n}[\mathrm{o}]$ muy reconcentrad[dos] les encargo por estar aquí 14 


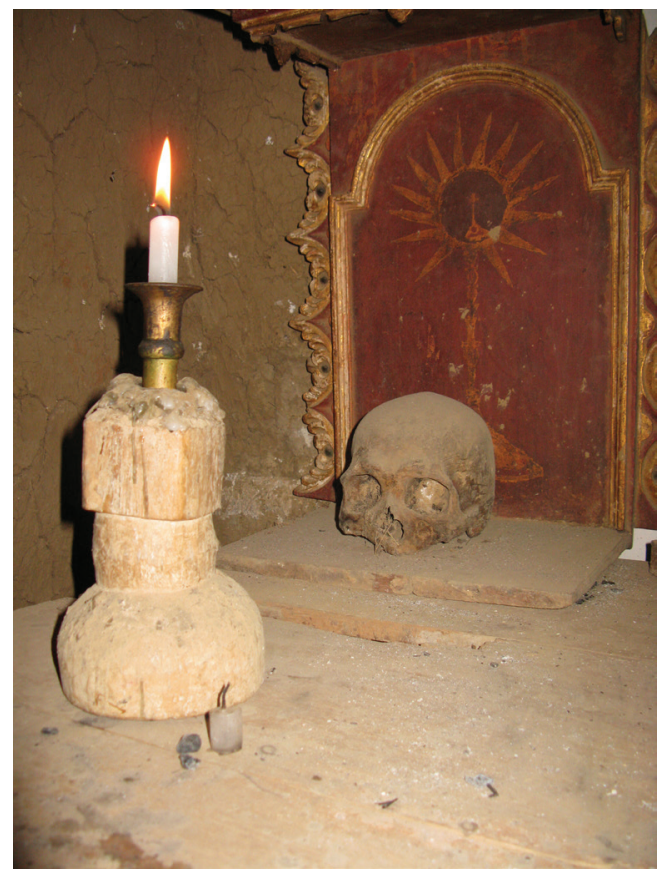

Figura 3: Supuesta calavera del último

sacerdote que habitaba en Incahuasi.

años y sé de ellos [ilegible] son amigos de Cumplimiento pero no para tenerlos como [ilegible] de verdaderos amigos, son pleitistas [ilegible]dos y aconsejan a esta gente para [ilegible] cuestiones curas [pero con]migo no an podido por llebarles lo [ilegible] $\mathrm{y}$ esto es [ilegible] que necesitan estos hasen[ilegible] llevarse con ellos indiferentes de lo contrario se bu[rlan] de uno, no dejar[los] a que ellos manejen este [ilegible] por que sería una perdision para Uds. esta la [ilegible] porque me a pasado con estos no hay que darles [ilegible] porque vienen a criticar del cura y a ponerlo mas miserable esto pues deseo que Uds. lleben [ilegible] para tener presente de todo, mostrarse en[ilegible] para todos tanto con esta gente como con los [ilegible] por que eso es lo que ellos quieren su humil[de] compañero que esta 14 años en este destierro».

Para comprender mejor este testimonio, debemos recordar, en primer lugar, no solo que Incahuasi y su templo fueron fundados en oposición a las haciendas y con el apoyo de la iglesia local, sino sobre todo que, incluso hasta hoy, la propiedad de la tierra en esta comunidad se legitima por medio de los rituales realizados por las cofradías en torno a las imágenes del templo. Así lo confirman las investigaciones de Alfredo Carrasco (2014) sobre los litigios seguidos por la iglesia a inicios de la segunda mitad del siglo XX. Carrasco transcribe varios documentos que corroboran que el actual sistema de legitimación de la propiedad de la tierra entre los incahuasinos se remonta, por lo menos, a la década de 1960:

«...desde muy antiguo los párrocos de Incahuasi han acostumbrado otorgar la conducción del fundo La Quesera a diversos colonos, preferentemente de padres a hijos, bajo el compromiso de encargarse de la celebración de la festividad de nuestro Señor Triunfante o sea el Domingo de Ramos» (Archivos del Juzgado de Paz de Incahuasi, citado en Carrasco 2014: 27). 
Figura 4: Interior de la iglesia de Incahuasi.

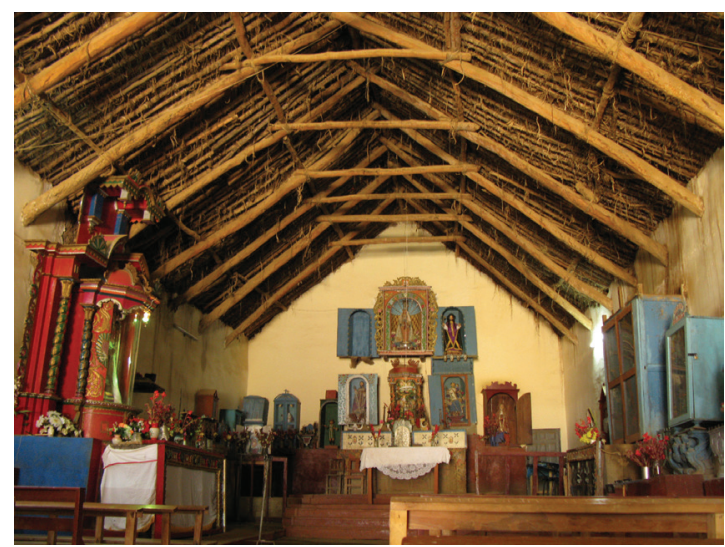

Así, ante el intento de la Sindicatura Eclesiástica de la Diócesis de Chiclayo de obtener los títulos supletorios sobre este fundo (La Quesera), los miembros de la comunidad de Incahuasi declaran que:

«...los terrenos que poseen los han heredado de sus anteriores con posesión de tiempo inmemoriales, y que es cierto que los párrocos administraban los bienes de la iglesia y que la creencia de que las tierras de Incahuasi eran de las Imágenes, fue dada por los párrocos que hace más de cincuenta años atrás venían a éste pueblo» (Archivos del Juzgado de Paz de Incahuasi, citado en Carrasco 2014: 28).

Durante nuestro propio trabajo de campo, más de medio siglo después del reconocimiento formal de la comunidad indígena y sus tierras colectivas (en 1963) ${ }^{12}$, los habitantes de Incahuasi todavía afirmaban que cada parcela de sus tierras «pertenecía» a una de las imágenes conservadas en su iglesia (Shaver 1992: 236; Vreeland 1993) (Figura 4). Esta adscripción al templo, sin embargo, parece haber menguado paulatinamente en beneficio de la «comunidad indígena». Así, cuando, en 1969 -es decir, apenas seis años después de su reconocimiento oficial-, un comunero solicita excluir ciertos fundos de las tierras de la comunidad y hacer una declaratoria de herederos, ésta arguye que:

«...los fundos... eran de propiedad de la Comunidad San Pablo de Incahuasi y que no existían propiedades individuales o particulares todas las tierras eran de la Comunidad... antes del reconocimiento de la Comunidad... la Iglesia no cobraba dinero en efectivo por poseer las tierras, sino que acostumbraban a obligatoriamente a celebrar la festividad por un lapso de cada año a los santos que les habían designado a cada viviente que poseían las tierras» (Archivos del Juzgado de Paz de Única Denominación de Incahuasi, citado en Carrasco 2014: 29).

12 No en 1937, como afirma Martínez (2014: 6). En la actualidad existen en Incahuasi seis comunidades campesinas: San Pablo de Incahuasi que incluye a la capital distrital, San Antonio de Laquipampa, Micaela Bastidas de Moyán, San Martín de Porres de Atumpampa, San Isidro Labrador de Marayhuaca y José Carlos Mariátegui. En lo que respecta al distrito de Cañaris, existen dos comunidades campesinas: San Juan de Cañaris y Túpac Amaru II. Finalmente, también encontramos en Salas dos comunidades: San Mateo de Penachí y San Francisco de Asís de Salas, aunque esta última se encuentre más bien en las tierras bajas. 
Aquella hipótesis que parecía desprenderse en 1777 del litigio por el diezmo -mencionado más arriba- entre la iglesia y los pueblos de indios de Incahuasi, que sólo treinta años antes había sido fundada con el apoyo de aquella, parece ser corroborada por el documento que acabamos de leer.

Ahora bien, a pesar de este aparente debilitamiento del papel de la iglesia en la administración de las tierras -lo que podría ser evidente, sobre todo hoy que ya no vive ningún párroco ni en Incahuasi ni en ningún otro pueblo del área Cañaris-, la legitimación ritual de la propiedad de la tierra se sigue sosteniendo. Esta persistencia se expresa hoy en dos planos, uno sincrónico y otro diacrónico.

En el primero, encontramos las formas en que se distribuyen los elementos arquitectónicos del templo: las columnas salomónicas de rostros tallados, las secciones del techo de paja y las imágenes veneradas que alberga en su interior.

Las columnas y el techo de la iglesia ya fueron descritos antes, cuando se mencionó la dimensión antropomorfa del templo: si las primeras son talladas con rostros humanos, el segundo es sometido a un ritual análogo al primer corte de pelo o «landa» de los niños.

Ahora bien, lo que no se ha mencionado hasta ahora es que, además, el techo de la iglesia se divide en dos mitades y trece secciones (si uno mira en dirección a la puerta principal, seis en el lado derecho de la viga de cumbrera y siete en su lado izquierdo ${ }^{13}$. Ahora bien, cada una de estas secciones está adscrita a uno de los distintos caseríos principales y más antiguos en que se divide la comunidad. Así pues, es posible verificar -de nuevo, como si se tratara de un mapa ideal hecho por los mismos comuneros-, la correspondencia entre ciertas partes del techo de la iglesia y cada uno de estos caseríos y grupos de familias que se asientan en las tierras de Incahuasi.

Las tres acciones arriba aludidas -el tallado de las columnas, el corte de la paja de los aleros y la renovación de cada sección del techo- se realizan cada cinco y diez años, cuando se juzga necesario renovar por completo los materiales de origen vegetal. Sin embargo, fuera del tiempo ritual, ambas características -la paja recortada de los aleros y las columnas salomónicas- se mantienen como tales a lo largo del tiempo ordinario (Figuras 5 y 6). Es decir, constituyen un aspecto sincrónico, propio de la estructura y organización visibles del templo. Es en este sentido en el que el templo de Incahuasi constituye una suerte de cartografía de la organización de los integrantes de la comunidad y de la distribución de las tierras entre las familias que la constituyen.

Ahora nos acercaremos a lo que hemos llamado el plano diacrónico, en el que podemos señalar dos dominios: uno mítico y el otro ritual. En el dominio mítico, hallamos los relatos orales sobre el origen y edificación del templo tal como son contados por los incahuasinos. Estos relatos que hemos recogido en Incahuasi, de carácter cosmogónico, describen el lugar donde se construyó la iglesia, aunque pueda causar sorpresa, como uno previamente inundado, lleno de agua y de vegetación,

13 Esta asimetría entre mitades recuerda un patrón que es visible en varios ritos andinos, por ejemplo, en los ritos ganaderos del valle de Chancay (Rivera 2003). En el lado derecho, de adelante hacia atrás, las secciones corresponden a las villas o caseríos de Sinchihual, Cutiquero, Huasicaj, Machaycaj, Totorita e Incahuasi. En el lado izquierdo, los caseríos son (también de atrás para adelante): Huar Huar, Tungula, Totora, Tranca, Tolojpampa, Tasjera y Playa. En todos los casos (a ambos lados de la viga de cumbrera), cada sección tiene la misma dimensión que las demás, con la excepción de la última sección de la mitad izquierda, que está dividida en dos: Playa y Tasajera. En consecuencia, estos dos caseríos deben hacerse cargo de la renovación de una porción del techo de la iglesia que es la mitad del tamaño que les corresponde a los otros caseríos. 


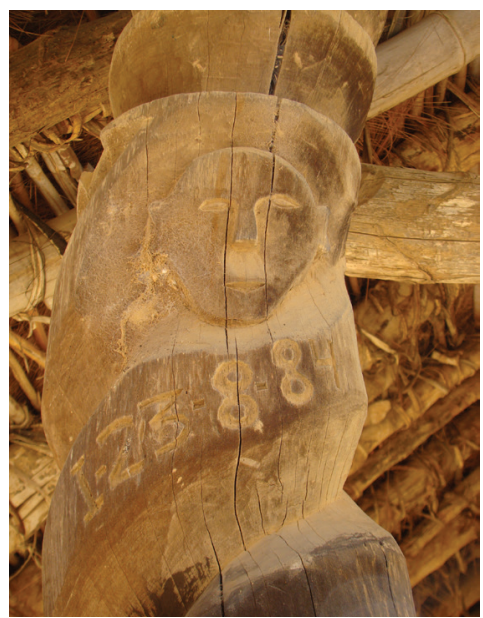

Figura 5: Detalle de columna salomónica con rostro esculpido.

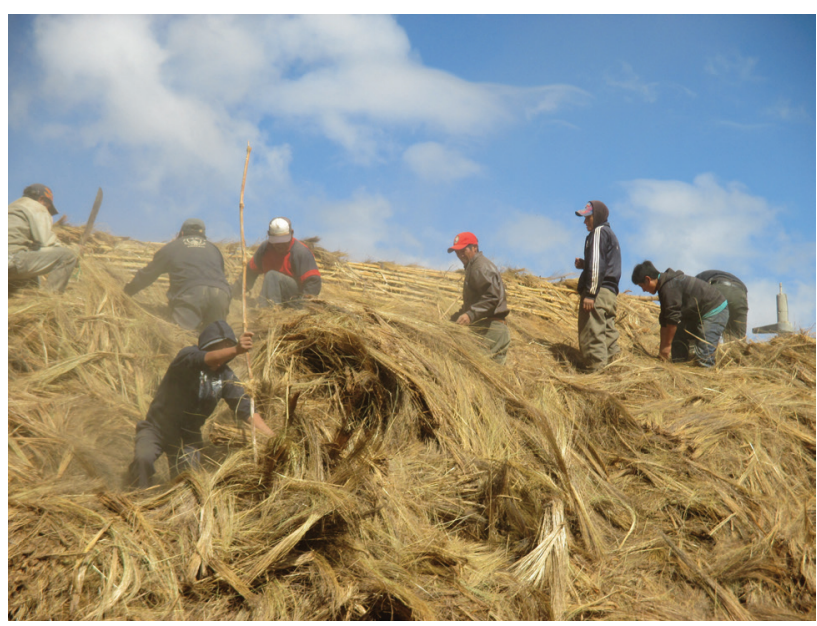

Figura 6: Trabajos de retechado de la iglesia de Incahuasi.

pues no parece haber rastros de esa suerte de pantano en la zona, aunque sí pareciera evocar aquel donde se realizan las celebraciones de San Juan, en Cañaris, después de sacar su imagen de la iglesia. Los incahuasinos afirman que el piso de su iglesia es todavía húmedo, que hay agua bajo sus suelos. Otros relatos hablan de un grupo de viajeros que pasaban por estos parajes y que por motivos diversos y a veces relacionados con ciertas mujeres, deciden participar de la edificación de la iglesia, donando monedas de oro y plata para fortalecer las cuatro esquinas del templo, en cuyas bases eran enterradas. Como puede verse, hay varios aspectos en la fundación mítica del pueblo. Sin embargo, sea como fuere, la iglesia y el pueblo surgen al mismo tiempo, sea en un páramo que los viajeros atraviesan apenas o en un pantano que es necesario secar antes de habitar. Y, además, surgen a partir de una transformación drástica del medioambiente, una que lo vuelve habitable para los humanos.

Ahora bien, en el dominio del rito encontramos el ciclo anual de festividades religiosas anuales de Incahuasi. Estas celebraciones son realizadas por las cofradías -dirigidas por un «cabezario», cuyo cargo es además hereditario-y tiene como centro a una de las imágenes del templo. Tal como lo hemos constatado en nuestro trabajo de campo y es sugerido por los archivos recogidos por Carrasco (2014: 30) y otros propios de la sacristía de la iglesia (archivo personal), el templo de Incahuasi tiene, pues, un carácter ordenador del tiempo. En efecto y tal como se ha estudiado en otros trabajos dedicados al mundo ritual andino, el templo, por medio de la celebración anual de las imágenes que alberga, funciona como una suerte de calendario.

A modo de ejemplo de lo señalado arriba, vale la pena acudir nuevamente a las hipótesis fundamentales de Peter Gose (1991) sobre el análisis de los ritos en torno a la inauguración de la vivienda conyugal ${ }^{14}$. Este estudioso, quizá el especialista que más profundamente ha reflexionado al respecto, enuncia en primer lugar que rituales

14 En Huaquirca, donde hiciera trabajo de campo, el wasichakuy contiene un elemento que evoca el templo: una cruz. En el grupo de varones que asciende a las alturas en busca de paja, uno debe hallar un atado 
como el wasichakuy expresarían unas contradicciones tácitas en la variación estacional que los enmarca (Gose 1991: 39-40). Para Gose, ambas estaciones, la seca y lluviosa, se encuentran marcadas por morales contradictorias, opuestas entre sí. Esta impronta hace que el cambio estacional implique una transformación en las relaciones sociales y en las formas de trabajo agrícola. Gose (1991: 42) señala una contradicción entre una apropiación privada y una producción colectiva, cuya base material serían las labores adaptadas a las distintas estaciones. Así, con el arribo de la estación lluviosa, por un lado, se relegará el énfasis en la apropiación privada, importante para los hogares durante la cosecha de la estación seca y, por otro lado, se enfatizará la cooperación interfamiliar extensa, propia de las labores agrícolas de la estación de lluvias. Es decir, cuando termina la estación seca, los campos pasan de ser un objeto de apropiación privada intrafamiliar a ser un objeto cooperación interfamiliar. El rito en torno al techado de la casa operaría, entonces, como un gozne entre dos momentos del año «moralmente» distintos. Así, por un lado, la culminación del techo de una casa constituye una metonimia de ella, de un hogar como unidad separada de residencia, como unidad de apropiación privada.

«...the founding of a new household in marriage... we are dealing with a two-stage process of synecdoche: first, the act of rethatching the roof is labeled 'house-making' in a more general sense, and then this 'house-making' comes to signify the formation of actual households. The roof exemplifies the house, which exemplifies the household... house rethatching within the annual cycle is used to depict the formation of household within the developmental cycle of domestic groups... in many parts of the Andes, people try to coordinate marriage with the phase of the annual cycle in which house rethatching takes place» (Gose 1991: 43).

Sin embargo, por otro lado, el wasichakuy está asociado también a lo que vendrá con el retorno de las lluvias: el trabajo cooperativo entre familias:

«If work on the roof is in some sense a development and completion of the part of the year dedicated to private appropriation, then we must also recognize that it brings together large work parties for the first time since the end of the rainy season in March, and thus that it anticipates the period of interhousehold cooperation that will recommence with the maize sowing in mid-September» (Gose 1991: 49).

Ahora bien, hay que señalar que la adscripción de ciertas parcelas de tierra y las cofradías religiosas en Incahuasi, que no tiene parangón en ningún otro pueblo del área cultural de Cañaris, así como tampoco su templo, pues los demás han sido destruidos, resulta así íntimamente relacionada con la fuerza que la vida ritual tiene en esta comunidad. Hoy en día, ninguna otra comunidad de esta región tiene tantos rituales y tantos participantes como Incahuasi.

Para terminar este breve y somero recuento de los datos disponibles sobre el papel del templo en la vida de los incahuasinos, valdría la pena considerar el acierto de aquellos indios de Penachí y Cañaris que expandieron su control sobre las tierras que los rodeaban, no solo comprándoselas a sus caciques, o batiéndose contra los abusos de los hacendados y gamonales usando todos los medios legales a su alcance, sino

con queso, semillas de maíz y alcohol que ha sido escondido expresamente para esta ocasión. Una vez que lo ha encontrado, retorna al pueblo y prepara la cruz de madera que se pondrá sobre el techo una vez terminado. 
también contraviniendo directamente las leyes que impedían la fundación de Incahuasi. En efecto, la historia parece mostrar, casi trescientos años después, cómo aquel pueblo clandestino que luchaba por su supervivencia entre poderosas haciendas, logra convertirse, finalmente, en la cabeza misma de la unidad política que hoy tiene como sus meros anexos o caseríos a los lugares cuyos antiguos dueños pretendían ser sus señores ${ }^{15}$.

La iglesia de Incahuasi es, pues, un buen reflejo de qué posiciones han predominado con el tiempo. Por un lado, las casas haciendas de la sierra yacen hoy o destruidas o abandonadas. Por el otro, dos edificios de cemento se han alzado ya en torno al peculiar templo de Incahuasi: la escuela pública y el municipio. Ambos casi cubren hoy la mirada de quienes llegan al pueblo, casi ocultan la iglesia. Incluso, más de un alcalde ha intentado recurrentemente «modernizar» el templo, sustituyendo sus materiales de paja y madera por cemento y zinc. Hace pocos años, mientras hacía mi trabajo de campo, se emplazaron, además de unas antenas de radio, unas torres de telefonía que permiten un acceso teóricamente ilimitado a un mundo cuya velocidad hoy cobra una fuerza cada vez mayor ${ }^{16}$.

\title{
5. Referencias bibliográficas
}

\author{
Alva Mariñas, Pedro \\ 1989 «El sitio arqueológico de Chiñama». Revista Alternativa (10): 111-126. Chiclayo. \\ 1995 «Congona: un sitio formativo en la serranía de Lambayeque». Avances. Apuntes \\ para la Investigación Regional 1: 9-24. Chiclayo. \\ 2008 «Don Víctor Huamán Reyes: el 'cacique moral' de Cañaris». Bulletin de l'Institut
}

\footnotetext{
15 Para un recuento de los acontecimientos en Incahuasi durante la segunda mitad del siglo XX, cf. Carrasco (2014: 42-49).

16 Antes de terminar, quisiéramos anotar tres tareas pendientes sobre la religión, la tierra y las políticas públicas que, por motivos de espacio, no hemos podido abordar aquí. La primera es la importantísima cuestión de la creciente población que abraza las formas de religiosidad protestantes, traídas a Incahuasi desde inicios de los ochenta por miembros del Instituto Linguístico de Verano y, en consecuencia, abomina de los ritos, la música y el consumo de alcohol asociados a la iglesia del pueblo. Además de los grupos sembrados por el ILV, varios alcaldes y otras autoridades parecen compartir una misma animadversión o indiferencia. Estos no solo han logrado deformar el templo, cambiando su fachada o transformando su campanario externo en vivienda, sino que algunos han propuesto incluso su sustitución por otro de cemento y zinc, como ha sucedido ya en Penachí, Janque o Cañaris. La segunda cuestión tiene que ver precisamente con la lucha por la tierra que ha cobrado bríos casi dramáticos en el contexto de un proyecto transnacional de minería a tajo abierto en el área Cañaris. Aunque el proyecto no concierne directamente a las tierras de la comunidad de Incahuasi, sino a las de la comunidad de Cañaris; los conflictos surgidos al respecto hace tiempo que han involucrado a los incahuasinos. La villa de Cañaris no cuenta con un templo del mismo tipo que Incahuasi, desde la destrucción del mismo que organizara su así llamado «cacique moral.» Finalmente, hay un tercer punto que atañe directamente al templo: los renovados intentos de volverlo un «patrimonio» de la nación. Tal iniciativa ya había sido tomada por el antropólogo norteamericano James Vreeland (1987), quien logra que el templo sea reconocido como patrimonio arquitectónico de Lambayeque en su breve paso por Incahuasi, hace más de un par de décadas (coincidentemente, los antropólogos que ahora buscan la «patrimonialización» de esta iglesia son también de origen no lambayecano). Al margen de la posible inutilidad de tales declaraciones por parte de un Estado que, como el peruano, ha dado la espalda a poblaciones como las de Incahuasi, creemos que hay un problema mayor en torno a estos esfuerzos. Nos referimos a los problemas asociados a la mercantilización que estas políticas públicas conllevan en países marcados por un neoliberalismo tan radical como el del Perú (Díaz Viana y Tomé 2007).
} 
Français d'Études Andines 37: 257-270.

2009 «Pachacamac en la Serranía Lambayecana», en Guía Educativa. Identidad Cultural Lambayecana. Chiclayo: Dirección Regional de Comercio Exterior y Turismo del Gobierno Regional Lambayeque.

2013 «Los cañaris de Lambayeque. Sus títulos coloniales». Chiclayo: INDER.

Bachmann, Carlos J.

1921 Departamento de Lambayeque. Monografía histórico-geográfica. Lima: Imprenta Torres Aguirre.

CARrasco Lucero, Alfredo

2008 Mis lecturas escogidas. Método Dolorier. Publicación propia.

2009 Método Dolorier: De Manolitos a Benjamines en el Lenguaje. Método Dolorier. Publicación propia.

2010 Método Dolorier: De Manolitos a Benjamines. Publicación propia.

2014 Incahuasi, notas para su historia. Ferreñafe: Cruz de Motupe.

CAstañeda León, Luisa

1981 Vestido tradicional del Perú. Lima: Museo Nacional de la Cultura Peruana.

Castañeda Murga, Juan, Carmen Espinoza Córdova y Eduardo Pimentel Carranza

2015 Templos virreinales de los valles de Lambayeque. Lima: USMP.

CIDEC

2013 Incahuasi, historia y tradiciones. Incahuasi: Municipalidad Distrital de Inkawasi.

DíAz Oliveros, Francisco Miguel y Carola Natalia Guevara EfFio

2007 Material educativo para docentes del nivel primaria como medio para la preservación de la identidad cultural en colegios de comunidades rurales a través del conocimiento de los elementos tradicionales de sus danzas folklóricas. Caso: «La Danza» en la festividad de la Virgen de las Mercedes (San Pablo de Inkawasi). Tesis para optar el título de docente en Educación Artística, Especialidad Folklore, Mención Danza. Lima: Escuela Nacional Superior de Folklore «José María Arguedas».

Díaz VianA, Luis y Pedro Tomé, eds.

2007 La tradición como reclamo. Antropología en Castilla y León. Salamanca: Junta de Castilla y León.

FERnÁndez Alvarado, Julio César

2009 «La etnia de los Cañaris en la región de Lambayeque en el norte del Perú», en Antiguas civilizaciones en la frontera de Ecuador y Perú. Una propuesta binacional para la integración andina, Quirino Olivera Núñez, ed., pp. 43-47. Lambayeque: Asociación Amigos del Museo de Sipán.

2010 «Cañaris del Norte y del Sur: Una visión desde el norte del Perú». Perspectiva Latinoamericana 7: 58-73. Documento electrónico, https://www.ic.nanzan-u.ac.jp/ LATIN/kanko/PL/2010PDF/05_JulioCesarFernandezAlvarado.pdf, con acceso el $11 / 03 / 2014$.

2011 «Campanas, retablos y mensajes en San Juan Bautista de Cañaris», en Lundero. Publicación Cultural de «La Industria» Chiclayo-Trujillo 385: 10-11.

2013 El proceso histórico de los Cañaris en la Región Lambayeque, Perú. Tesis de doctorado en Bienestar Social y Desarrollo Local. Chiclayo: Universidad Católica Santo Toribio de Mogrovejo. 
Gose, Peter

1991 «House Rethatching in an Andean Annual Cycle: Practice, Meaning and Contradiction». American Ethnologist 18 (1): 39-66.

GroEnEWALD, Ronel

2011a «El tejido y la cultura. El significado de los tejidos en Inkawasi», en Una mirada al mundo quechua: Aspectos culturales de comunidades quechuahablantes., David Coombs, ed., pp. 255-272. Lima: Instituto Lingüístico de Verano. Documento electrónico, http://www-01.sil.org/acpub/repository/Una_Mirada_v_Cover_web_ Feb28_2012_2.pdf, con acceso el 02/04/2014.

2011 b «Pácticas y creencias sobre el embarazo entre los quechuahablantes de Inkawasi», en Una mirada al mundo quechua: Aspectos culturales de comunidades quechuahablantes, David Coombs, ed., pp. 183-215. Lima: Instituto Lingüístico de Verano. Documento electrónico, http://www-01.sil.org/acpub/repository/Una Mirada_v_Cover_web_Feb28_2012_2.pdf, con acceso el 02/04/2014.

HUAMÁN, Joaquín

2008 Mitos y leyendas de Cañaris. Chiclayo: Ediciones Prometeo Desencadenado.

HuERTAS, Lorenzo

1996 «Patrones de asentamiento poblacional en Piura (1532-1850)». Bulletin de l'Institut Français d'Études Andines 25 (1): 91-124.

INGOLD, Tim

2013 Making: Anthropology, Archaeology, Art and Architecture. Londres: Routledge.

IngOLD, Tim y Philippe Descola

2014 Etre au monde. Quelle expérience commune? Lyon: PUL.

MARTínez SANTAMARÍA, Luz

2014 Iglesia de San Pablo. Tesoro arquitectónico y cultura viva de Incahuasi. Chiclayo: Lora y Cordero.

Morote Best, Efraín

1988 Aldeas sumergidas. Cuzco: Centro Bartolomé de las Casas.

MuÑoz MoRÁn, Oscar

2012 «Casas y no-casas entre los quechuas. Habitar el tiempo en una comunidad de Potosí, Bolivia». Diálogo Andino 39: 73-84.

Palomino, Salvador

1984 El sistema de oposiciones en la comunidad de Sarhua. La complementariedad de los opuestos en la cultura andina. Lima: Pueblo Indio.

Platt, Tristan

2001 «El feto agresivo. Parto, formación de la persona y mito-historia en los Andes». Anuario de Estudios Americanos 58 (2): 633-678.

RAIMONDI, Antonio

1965 El Perú [1876], edición facsimilar. Lima: Editores Técnicos Asociados S.A.

RIVERA ANDÍA, Juan Javier

2003 La fiesta del ganado en el valle de Chancay. Lima: PUCP.

2010a «La dulzaina de la sierra de Lambayeque». Diario Oficial El Peruano (Suplemento Variedades), 01/11/2010.

2010b «El pinkullo en los pueblos de la sierra de Lambayeque. Flauta lambayecana». 
Diario Oficial El Peruano (Suplemento Variedades), 15/11/ 2010.

2011 «Una flauta traversa tañida por interpretes femeninos en la sierra norte peruana». Estudios Latinoamericanos 31: 127-144.

2013a «Una organología tradicional de los Andes septentrionales peruanos. En torno a los instrumentos musicales de la sierra de Lambayeque (distrito de Cañaris, provincia de Ferreñafe)». Anthropos 108 (2): 463-480.

2013 b «Un patrimonio cultural ignorado y en riesgo en los Andes septentrionales del Perú. Apuntes etnográficos sobre dos instrumentos musicales endémicos de la sierra de Lambayeque», en Wege im Garten der Ethnologie. Zwischen dort und hier. Festschrift für María Susana Cipolletti, Hanna Heinrich y Harald Grauer, eds., pp. 285-306. Collectanea Instituti Anthropos, 46. Sankt Augustin: Anthropos Institut.

2014a «Comparaison entre la herranza, la 'fête de l'eau' et la zafa-casa dans les Andes». Recherches Amerindiennes au Quebec 44 (2-3): 39-48.

$2014 b$ «Fuentes para el estudio de una región 'invisible' de los Andes peruanos. Contribución para una bibliografía exhaustiva sobre la sociedad y la naturaleza en la Sierra de Lambayeque, Perú». Anuario Americanista Europeo 12: 47-77.

e.p. «¿Quiénes son los cañaris del Perú? Apuntes etnográficos e históricos sobre un pueblo ignorado y amenazado en la sierra de Ferreñafe», en Actas del 54 ICA (Simposio 808): Geografía sagrada de los Andes Ecuatoriales y Centrales: Una comparación macroregional, Alden Yépez, ed. Quito: PUCE.

SAx, Marieka

2014 Sorcery and Morality in the Andes: Illness, Healing, and Brujería in Kañaris (Lambayeque, Peru). Tesis de doctorado. Universidad de Carleton.

SHAVER, Dwight

1989 «Las costumbres sociales relacionadas con el consumo de bebidas alcohólicas entre los quechua de Incahuasi», en Estudios etno-lingüísticos I, Stephen Parker, ed., pp. 97-104. Documento de Trabajo, 21. Lima: Ministerio de Educación, Instituto Lingüístico de Verano.

1992 «Organización socio-política de las comunidades campesinas: el caso de Inkawasi», en Estudios etno-lingüísticos II, Stephen Parker, ed., pp. 224-256. Documento de Trabajo, 23. Lima: Ministerio de Educación, Instituto Lingüístico de Verano.

TAYlor, Gerald, Susana AldANA y Jean Louis ChALÉARD

2006 «Les bouleversements des hiérarchies territoriales au Pérou», en La mondialisation côté Sud: Acteurs et territoires, Jérôme Lombard et al., eds., pp. 249-271. París: IRD-Éditions.

VREELAND, James M.

1987 Dossier para la solicitud al Instituto Nacional de Cultura de la restauración de la iglesia de San Pablo de Incahuasi. Lima: Archivos del Ministerio de Cultura.

1993 «Danzas tradicionales de la sierra de Lambayeque», en Música, danzas y máscaras en los Andes, Raúl R. Romero, ed., pp. 179-217. Lima: Pontificia Universidad Católica del Perú.

Zuidema, Tom

1995 El sistema de ceques del Cuzco: la organización de la capital de los Incas. Lima: Pontificia Universidad Católica del Perú. 